\title{
Cow Cement Sensor Based On Coil - Resistance Temperature Detector (C-RTD) Coupled With Four Wire Configuration Bridge (4-WCB)
}

\author{
Moh. Toifur and Bagus Haryadi \\ Physics Dept., Faculty of Mathematics and Natural Sciences Ahmad Dahlan University, Jl. Prof. Dr. Soepomo, \\ Janturan Umbulharjo Yogyakarta Indonesia 55165. \\ email:mtoifur@yahoo.com \\ Riswanto \\ Magister of Physics Education, Post Graduate Program, Ahmad Dahlan University Yogyakarta, Indonesia 55161.
}

\begin{abstract}
Low Temperature Detection System on cow cement flask base on RTD-coil coupled by transducer 4-WCB has been made. Four kinds of sensor was prepared, that's are coils from copper material with diameter $1 \mathrm{~mm}$ and set number of winding from 200 up to 500. Four-WCB circuit was chosen as transducer to facilitate the output voltage and to avoid the self heating on a wire directly connected with sensor. Liquid nitrogen is used as medium which its temperature will be measured. Temperature of medium was varied from $-130^{\circ} \mathrm{C}$ up to $0^{\circ} \mathrm{C}$. Collecting data was done on temperature and output voltage and output voltage was taken on each rising temperature of medium. Data temperature-voltage was analyzed by curve fitting according to quadratic polynomial $y=a x^{2}+b x+c$. Sensitivity level of sensor was determined from slope of graphics, whereas the level of stability of sensor was determined from standard deviation. From plot of temperature - voltage data, it is known that all of sensors consistently tend to follow polynomial orde- 2 form. It is found that sensor with the number of windings 400 is the most sensitive, but less stable compared with sensor 200 windings. Equation for potential $(V)$ as function of temperature $(T)$ concerning with sensor 400 windings is $V=-0.00003 T^{2}+0.32 T+77.09$. This sensor has sensitivity and stability levels are $0,32 \mathrm{mV} /{ }^{\circ} \mathrm{C}$ and $R^{2}=0,99$ respectively.
\end{abstract}

Keywords: cow cement, coil-RTD, 4 WCB, low temperature.

\section{Introduction}

The low temperature sensor in flask cow cement currently is urgently needed. This is concerning to an effort to keep quality of cement ${ }^{1,2}$. The disturb of cement is frequently caused by the rising temperature in the space inner flask containing liquid nitrogen ${ }^{3}$. The temperature of liquid nitrogen is about $-196^{\circ} \mathrm{C}$. During about 2 weeks the liquid nitrogen will be lost due to evaporation to environment. Again by frequently openclose the cap of flask the nitrogen gas will exit from flask. The escaping nitrogen gas will rising temperature at inner flask. If temperature at inner flask increase up to $10^{\circ} \mathrm{C}$, cow sperm in cement will death. Until now there is no instrument that monitor the existence of liquid nitrogen in flask.

One of method for detecting the existence of liquid nitrogen in flask is investigating its temperature using
Coil-Resistance Temperature Detector (C-RTD). RTD is temperature detector based on change of resistance that sensitive toward the change of temperature. RTD has an advantages compared to other methods such as thermocouple that not have ability to be used for measuring the low temperature medium, or thermometer that has limitation for measuring the low and the high temperature.

At research before, it was designed the low temperature sensor using copper wire formed into a solenoid to be used as sensor. By varied diameters of wire from $0.1 \mathrm{~mm}$ to $0.3 \mathrm{~mm}$ and the varied number of winding from 3.000 to 12.000 , we investigate the magnetic susceptibility at each temperature set from $120^{\circ} \mathrm{C}$ up to $0^{\circ} \mathrm{C}$. The results show that there is no certain relation between temperature and susceptibility. In the low temperature sensor not perform the magnetic properties ${ }^{4}$. Then the research be directed to investigate 
the electric properties of coil if it is exposure in the low temperature medium.

In this research to produce the true voltage on sensor we improve the type of transducer configuration from 3 $\mathrm{WCB}$ to $4-\mathrm{WCB}$. In the $3-\mathrm{WCB}$ as revealed by ${ }^{5}$ the measured voltage is not only from sensor but also from wire connecting the sensor and the resistor. The longer the wire the larger the addition voltage. Again according to the flowing of current, temperature of wire will increase, and this is cause the increasing resistance ${ }^{4}$. This phenomenon is called as self heating and is a seriously problem in domain of temperature sensor. In 4-WCB, two output voltage probes directly measured at the end of coil sensor. With this method self heating can be avoided so that the measured voltage is more depict the actual voltage from sensor.

\section{The Experiment Procedure}

The sequences of process in this experiment be depicted by block diagram as in fig. 1 .

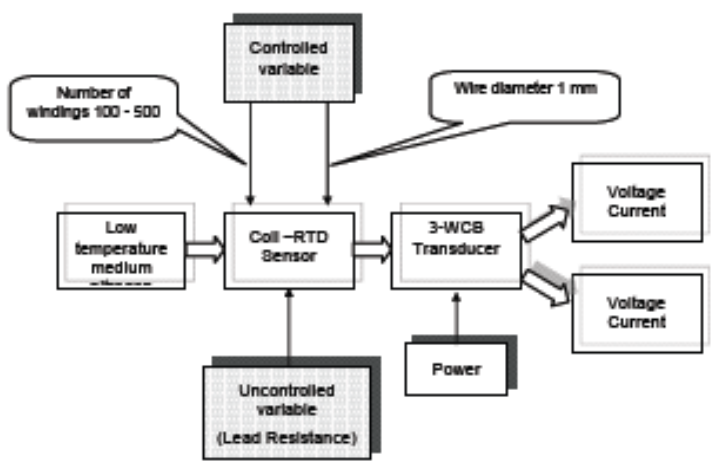

Fig. 1. Block diagram of experiment

Copper wire with different diameters are $0.1 \mathrm{~mm}$ is formed into coils with a diameter of $(0.528 \pm 0.005) \mathrm{cm}$. Each coil is varied on number of windings from 200 to 500. These coils were treated as temperature sensors. As showed at fig. 3, the coil was connected to 4-WCB transducer that used three resistors in its circuit that's are $200 \Omega$ respectively. Device is supplied by 3 volt DC power. The sensor is inserted within $250 \mathrm{ml}$ Erlenmeyer tube that has been filled with liquid nitrogen as a low temperature medium. The temperature was measured by thermocouple, and the voltage was measured by multimaster type Extech 570 True RMS. Setting of medium temperature (from $-130^{\circ} \mathrm{C}$ to $0^{\circ} \mathrm{C}$ ) was done by evaporating nitrogen gas. At any rising temperature, the voltage is recorded.

From pictograph of temperature-voltage data points resulted from each sample, then data is fitted according to quadratic polynomial $y=a x^{2}+b x+c^{6}$. The strength of relation between the two variables will be described by through index of determination $\left(R^{2}\right)$, whereas stability level of sensor was carried out from standard deviation of data.

The next, characteristic of each equation could be detaily investigated from the value of coefficients $a, b$, and $c$. The $a$ illustrates level curvature of the curve, $b$ describe the slope of graphic whereas $c$ is intercept. However, among these three parameter, $b$ held the important role to give characteristic of sensor because $b$ value determine the sensitivity level of sensor. The larger $b$ the more sensitive sensor.

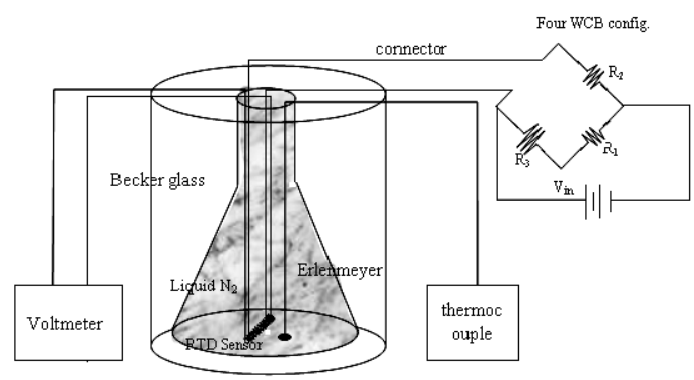

Fig. 3. Schematic diagram of arrangement of equipment for experiment

\section{Result and Discussion}

In fig. 4 it is showed a graphically description of the relationship between voltage and temperature of medium for various number of windings. From data fitting of voltage-temperature produce equations according to second order polynomial.

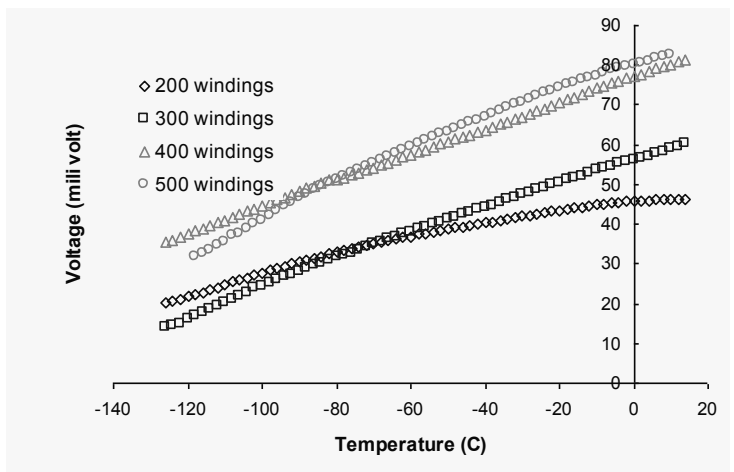

Fig. 4. Output voltage from transducer 4-WCB at each of change temperature 
Table 1. Equation represent relationship between voltage and temperature for each sample.

\begin{tabular}{|c|c|c|c|c|}
\hline No & $\begin{array}{c}\text { Sample Number } \\
\text { of windings }\end{array}$ & $\begin{array}{c}\text { Equation of voltage }(y) \text { as function } \\
\text { of temperature }(x) \text { in } \mathrm{mV}\end{array}$ & $\begin{array}{c}\text { Standart } \\
\text { deviation }\end{array}$ & $\begin{array}{c}\text { Determination } \\
\text { index, } R^{2}\end{array}$ \\
\hline 1 & 200 & $y=-0.0008 x^{2}+0.10 x+45.72$ & 4.6 & 0.9964 \\
\hline 2 & 300 & $y=-0.0004 x^{2}+0.28 x+56.13$ & 5.0 & 0.9989 \\
\hline 3 & 400 & $y=-0.00003 x^{2}+0.32 x+77.09$ & 7.4 & 0.9995 \\
\hline 4 & 500 & $y=-0.0006 x^{2}+0.33 x+80.56$ & 8.1 & 0.9996 \\
\hline
\end{tabular}

The equations are shown in Table 1. From table 1, it is appear that all samples perform a consistent relationship between temperature and voltage. The data tend to follow the $2^{\text {nd }}$ order polynomial $\left(y=a x^{2}+b x+\right.$ c) at temperature ranging from $-140 \mathrm{C}$ up to $0^{\circ} \mathrm{C}$. This is suitable with Callendar-Van Dusen formula ${ }^{7}$.

The goodness of fitting is indicated by the value of determination index, that is more than 0.95 for all samples. The meaning is at all sample it is found the strong relationship between temperature and voltage for temperature ranging from $-130^{\circ} \mathrm{C}$ to $0^{\circ} \mathrm{C}$.

The $b$ values is vary from sample to sample, and have a good particular tendency, that are the more number of windings the larger the $b$ value. This is due to the larger number of windings the larger surface area of wire that contact with environment. This is cause the sensor to be more sensitive.

Beside that from $a$ and $b$ values it is possible to identified the level of curvature and linearity of curve. A good sensor have linier relationship between temperature and voltage, so that from a combination of $a$ and $b$ values it is possible to determine which the curve that have the best level of linearity. From graph it is appear that sample 400 windings is the most linier compared with others. This sample have $a=0.00003$ $\mathrm{mV} /{ }^{\circ} \mathrm{C}^{2}$ and $b=0.32 \mathrm{~V} /{ }^{\circ} \mathrm{C}$. This $a$ value is most little whereas the $b$ value is the largest. It mean that this sample have the highest sensitivity and linearity levels. The mean of sensitivity $0.32 \mathrm{~V} /{ }^{\circ} \mathrm{C}$ is for each of rising of temperature $1{ }^{\circ} \mathrm{C}$ will rising a potential different 0.32 $\mathrm{mV}$.

\section{Conclusions}

From the discussion above, we take a conclusion such as follows:
It has been produced cow cement temperature sensor using coil-RTD enhanced with transducer 4WCB.

Coil sensor with diameter $1 \mathrm{~mm}, 400$ windings is the most sensitive and the most stable compared with the same diameter and another number of windings for sensing temperature ranging from $-130^{\circ} \mathrm{C}$ up to $0^{\circ} \mathrm{C}$.

\section{Acknowledgement}

The author thanks to Ministry of National Education and Culture for funding through the Hibah Bersaing Grant 2013-2014.

\section{References}

1. E. S. E. Hafez. Preservation and Cryopreservation of Gametes and Embryos. In Reproduction in Farm Animals. 7th ed. E. S. E. Hafez and B. Hafez (eds) (Lippincot Williams \& Wilkins, Philadelphia, 2000).

2. D.L.Garner and E. S. E. Hafez. Spermatozoa and seminal plasma. In: Reproduction in Farm Animals. 7th ed. E. S. E. Hafez and B. Hafez (eds). (Lippincot Williams \& Wilkins, Philadelphia, 2000).

3. H. Paulenz, L. Soderquist, R. Perez-Pe and K.A. Berg. 2002. Effect of Different Extender and Storage Temperatures on Sperm Viability of liquid Ram spermatozoa. Theriogenology 57 (2002) 823-836.

4. M. Toifur, Prototype Of Low Temperature Sensor Based On Resistance Temperature Detector-Coils Enhanced with Three Wire Configurations Bridge (3-WCB), Paper in International Conference on Advanced Material and Practical Nanotechnology ICAMPS 2014) (Jakarta, Indonesia, 2014).

5. A. O'Grady, Transducer/Sensor Excitation and Measurement Techniques, Analog Dialogue, 34 (5), 2000.

6. R. R.Bevington, \& D.K. Robinson. Data Reduction and Error Analysis for The Physical Sciences. (Singapore: McGraw-Hill Book, 1992).

7. Potter, Measuring Temperature with RTDs, National Instrumen, the software is the instrumen, Appl. Note 046, (National Instrumen Coorporation, 1993) 